\title{
Controlling the spread of COVID-19 in Sudan with limited resources: a unique community-engaged approach
}

Gasmelseed Ahmed, ${ }^{1}$ Yassir Mohamed, ${ }^{2}$ Razi Adulhameed, ${ }^{3}$ Majdi Ishag ${ }^{4}$ and Ahamed Elzubair ${ }^{5}$

${ }^{1}$ Almoosa Specialist Hospital, Al Mubarraz, Saudi Arabia. ${ }^{2}$ Prince Sultan Military Medical City, Riyadh, Saudi Arabia. ${ }^{3}$ King Saud University Medical City, Riyadh, Saudi Arabia. ${ }^{4}$ King Abdulaziz Medical City, Al-Ahsa, Saudi Arabia. ${ }^{5}$ Alwatania University, Khartoum, Sudan. (Correspondence to: Gasmelseed Y. Ahmed: g.yousif@almoosahospital.com.sa).

Citation: Gasmelseed YA; Mohamed Y; Adulhameed R; Ishag M; Elzubair AG. Controlling the spread of COVID-19 in Sudan with limited resources: a unique community-engaged approach. East Mediterr Health J. 2020;26(6):636-637. https://doi.org/10.26719/emhj.20.072

Received: 04/05/20; accepted: 27/05/20

Copyright (C) World Health Organization (WHO) 2020. Open Access. Some rights reserved. This work is available under the CC BY-NC-SA 3.o IGO license (https://creativecommons.org/licenses/by-nc-sa/3.o/igo).

\section{Introduction}

Coronavirus disease 2019 (COVID-19) is an infectious disease caused by severe acute respiratory syndrome coronavirus 2 (SARS-CoV-2). It spreads by droplets and from contaminated solid surfaces. (1-2). Since December 2019, there had been a series of unexplained cases of pneumonia reported in Wuhan, China, and on 12 January 2020, the World Health Organization (WHO) named this new virus as the 2019 novel coronavirus (2019-nCoV) (3). SARS$\mathrm{CoV}-2$ is a coronavirus belongs to the $\beta$-coronavirus cluster, it is the third zoonotic coronavirus disease after SARS and the Middle East respiratory syndrome (MERS) (4).

Responsibility for health involves the joint effort of the individual, the community and the state, and emphasis has shifted from health care for the people to health care by the people (5). This initiative was adopted to suit the inadequate medical resources in Sudan through engaging the community under medical supervision. These are societal actions based on donated locations for infected peoples and dormitories for care providers; controlling the infection as soon as discovered by isolating certain cases at home, others in quarantine, and transfer critical cases to hospitals; avoiding gatherings even for religious activities; closing borders; modifying workflow; remote schooling and online college classes. Moreover, access to health information from reliable sites included, but not limited to, the Sudanese diaspora's websites for health education and global updates.

Known preventive measures such as respiratory hygiene, cough etiquette (covering the nose and mouth when coughing), wearing a mask, frequent hand washing, cleaning and disinfection of surfaces, social distancing, avoiding social gatherings and handshaking, and refraining from touching the face, go simultaneously with the initiative. The two success pillars are medical volunteers working together and supervision of nonmedical volunteers. The initiative was shared with the minster of heath who supported the idea and referred it to the ministry's officials. It has not as yet been adopted as national policy, but discussions with local communities are suggested, and accordingly pilot operations in some areas with support of local health officials have commenced, as follows:

\section{Volunteer health personnel within the neighbourhood}

Licensed heath care personnel are assigned to provide hotline communication between health practitioners trained in community outreach and a control room in the nearest Ministry of Health $(\mathrm{MoH})$ facility, in order to decide and supervise isolation in the neighborhood and guide local non-medical volunteers. In addition, they perform a therapeutic and educational role for isolated individuals and their families with continuous evaluation of cases that require hospitalization. The initiative is subject to ongoing evaluation for identification of logistic obstacles and amendments as required.

\section{Neighbourhood non-medical volunteers}

Non-medical volunteers supervise the donation of a house or a commercial site for isolation and urge the community to interact positively with instructors, as well as assist in health education and facilitate the tasks of the health care providers. They also prevent gatherings inside the neighbourhood, with the exception of funerals, but with the lowest possible number of attendees and done in the quickest time possible. Other duties include managing social and physical distancing in the neighbourhood and public places such as central markets; advise travellers and drivers on the importance of using hand sanitizer, cleaning surfaces and opening windows for ventilation, while also providing them with educational materials, and establishing fixed washing units for soap, water and sanitizer in taxis.

\section{Home isolation}

The health team decides when isolation is required based on the policies of the Ministry of Health, and educate isolated persons via telephone on the safety of their families, friends and neighbours, and deliver tissues, masks, soap and disinfectants for two weeks.

\section{Neighbourhood quarantine isolation}

Procedures for neighbourhood quarantine isolation in- 
clude the location of a building on one of the outskirts of the neighbourhood, such as a house, school, club or a commercial complex. The selected building should be well ventilated, comfortable and have basic facilities such as water, electricity, toilets and supervised waste disposal measures. Volunteers are assigned to provide food and water in accordance with quarantine standards, and organize transportation in case a patient needs to be hospitalized. The quarantine area is equipped for measuring vital signs, with the health officer and the team using preventative measures such as wearing masks, using disinfectants, ventilating the rooms and all other infection control procedures. Required personal protective equipment (PPE) are partially supplied by the $\mathrm{MoH}$, and the remainder by donation.

In conclusion, this initiative provides a basis for infection control guidelines in low and middle-income countries. However, the initiative is limited by the lack of similar evidence-based experience for comparison and the shortage of trained staff. Still, the initiative offers a turning point in promoting an atmosphere of cooperation within the community and its application in social behavior for public health practice. Currently, an evaluation of the efficacy of this initiative is underway.

\section{Acknowledgments}

The authors would like to acknowledge Dr. Nazik Mahmoud and Dr. Ahmed Hussain for facilitating the pilot strategy with the efforts of the Sudanese Resistance Committee in Buri, whose efforts were highly appreciated. Thanks are also extended to the Sudanese Doctors Committee in the Gulf region.

\section{References}

1. Okbaı NMA, Müller MA, Li W, Wang C, GeurtsvanKessel CH, Corman VM, et al. Severe acute respiratory syndrome coronavirus 2 - specific antibody responses in coronavirus disease 2019 patients. Emerg Infect Dis. 2020 Jul doi:10.3201/eid2607.200841

2. Hui DS, Azhar EI, Madani TA, Ntoumi F, Kock R, Dar O, et al. The continuing 2019-nCoV epidemic threat of novel coronaviruses to global health. The latest 2019 novel coronavirus outbreak in Wuhan, China. Int J Infect Dis. 2020 Feb;91:264-266. doi:10.1016/j. ijid.2020.01.009

3. Wang W, Tang J, Wei F. Updated understanding of the outbreak of 2019 novel coronavirus (2019-nCoV) in Wuhan, China. J Med Virol. January 2020;92:441-447. doi:10.1002/jmv.25689|

4. Chen Y, Liu Q, Guo D. Emerging coronaviruses: genome structure, replication, and pathogenesis. J Med Virol. 2020; 92: 418-423. doi: 10.1002/jmv.25681.

5. Park's textbook of preventive and social medicine. K. Park. 2oth edition (2017) Jabalpur: Banarsidas Bhanot Publishers. 